\title{
Case Report of Prosthetic Treatment of a Young Patient Suffering Papilon-Lefever Syndrome
}

\author{
Masoumeh Rostamzadeh $^{1 *}$, Ghasem Omati Shabestari², Mohammad Rastegar Khosravi ${ }^{3}$ \\ ${ }^{1}$ Department of Prosthodontics, Faculty of Dentistry, Kurdistan University of Medical Science, Sanandaj, Iran \\ ${ }^{2}$ Department of Prosthodontics, Faculty of Dentistry, Tehran University of Medical Science, Tehran, Iran \\ ${ }^{3}$ Department of Endodontics, Faculty of Dentistry, Kurdistan University of Medical Science, Sanandaj, Ira \\ Email: *masomehrostamzadeh460@gmail.com
}

How to cite this paper: Rostamzadeh, M., Shabestari, G.O. and Khosravi, M.R. (2017) Case Report of Prosthetic Treatment of a Young Patient Suffering Papilon-Lefever Syndrome. International Journal of Clinical Medicine, 8, 422-429.

https://doi.org/10.4236/ijcm.2017.86040

Received: April 12, 2017

Accepted: June 25, 2017

Published: June 28, 2017

Copyright $\odot 2017$ by authors and Scientific Research Publishing Inc. This work is licensed under the Creative Commons Attribution International License (CC BY 4.0).

http://creativecommons.org/licenses/by/4.0/

\begin{abstract}
Papillon-Lefevre syndrome (PLS) is a rare recessive autosomal disease which occurs with palms and soles hyperkeratosis as well as primary and permanent teeth periodontal loss. Recently, it has been proved that a mutation at Cathepsin gene $\mathrm{C}$ is the genetic cause of PLS. All primary and permanent teeth of the patients are lost at ages 2 or 3 because of serious alveolar bone destruction. This paper presents a complete case of prosthetic treatment of an 8-year old girl with PLS.
\end{abstract}

\section{Keywords}

Prosthetic Treatment, Young Patient, Papilon-Lefever Syndrome

\section{Introduction}

Lefevre and Papillon first explained this syndrome which is called by their name in 1924. Inheritance pattern of this disease is Mendelian recessive autosome. This disease has some oral and skin demonstrations. Its outbreak is 1 - 4 million and carrier genes are 2 - 4 in every 1000 people. The skin symptoms are obvious in 3 first year of life as palm and sole keratosis in most patients. Diffused follicular hyperkeratosis and elbows and knees keratosis are rarely reported [1].

Oral symptoms include aggressive periodontitis in primary and permanent teeth. Severe periodontal damage causes loss of primary before age 4 [2]. After loss of the teeth, gum inflammation disappears and gums form normally. Periodontal damage begins after permanent teeth growth and gum inflammation that advances rapidly. Alveolar bone damage happens in two or three years and patients lose their whole teeth before age 15 - 16.

Patients with this illness have a high potential for infections including Middle ear infection, pneumonia, diphtheria liver abscess. Ectopic calcification in the 
area of dura mater is seen in some patients but it is not considered as one of the clinical characteristics of the illness [3].

Clinical diagnosis was determined based on palmar and plantar hyperkeratosis associated with aggressive periodontitis in primary and permanent teeth.

It is inevitable to use dental prosthesis at this low age and the prosthesis must be made with regards to maintain the dental free ridge. Using narrow posterior teeth, reduction of vertical height of occlusion, reduction of posterior teeth number and less use of the prosthesis will lead to less loss of the ridge in long terms [4].

Dental implants were installed successfully for this patient.

\section{Case Explanation}

A little 8-year old girl (Figure 1) with early complaints of looseness of permanent teeth soon after their eruption with full Edentulous referred to Dentistry department of Tehran University. Panoramic radiography of ages 4, 5, 6, 7 of the patient was available (Figures 2-5). The patient underwent follow-up process and teeth with acute periodontal problems were removed from her mouth.

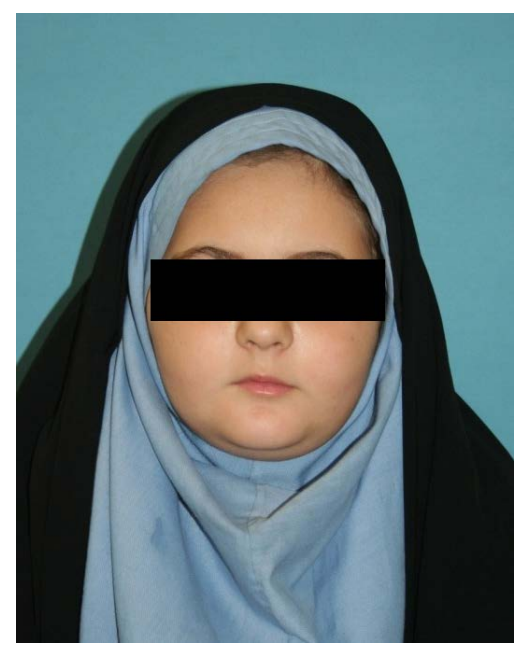

Figure 1. A little 8-year old girl.

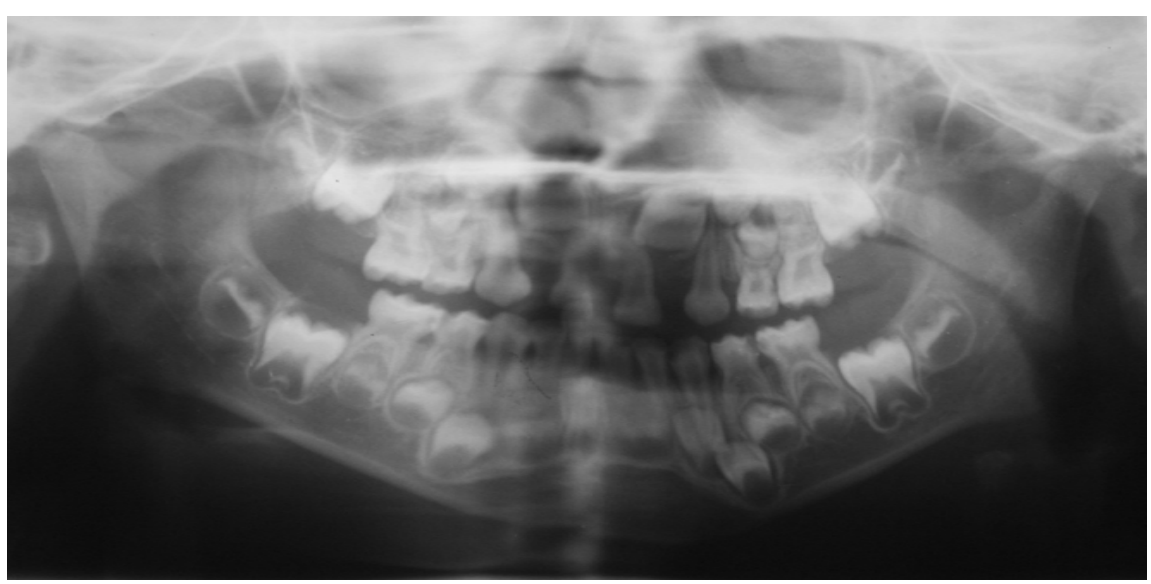

Figure 2. Panoramic radiography at age 4 . 


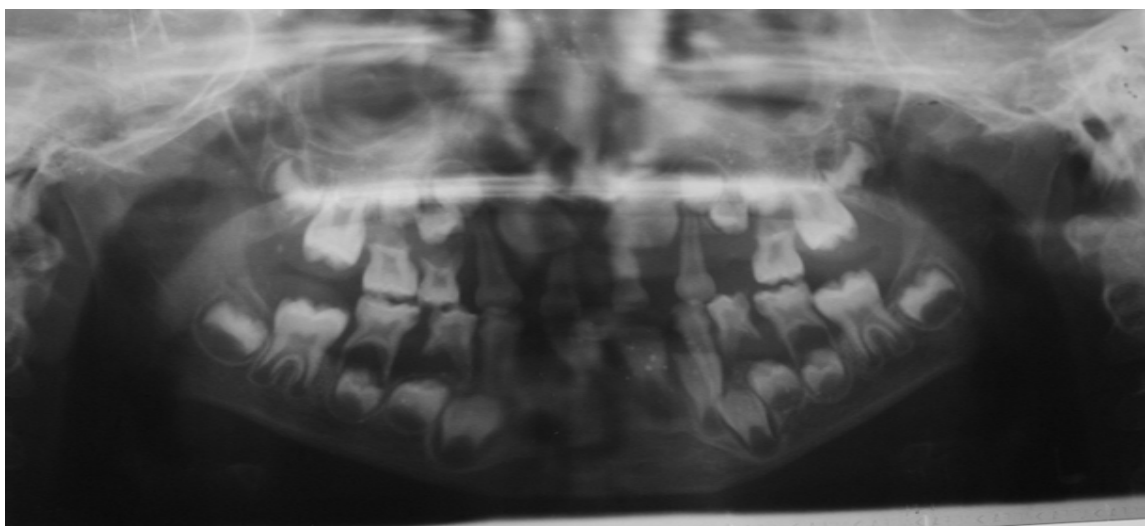

Figure 3. Panoramic radiography at age 5.

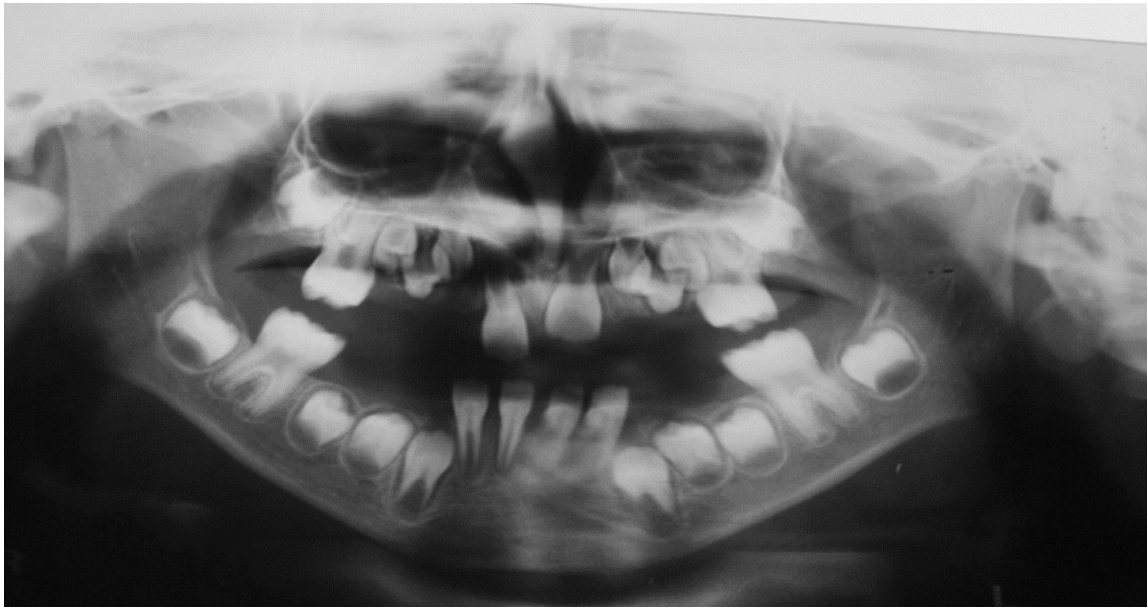

Figure 4. Panoramic radiography at age 6.

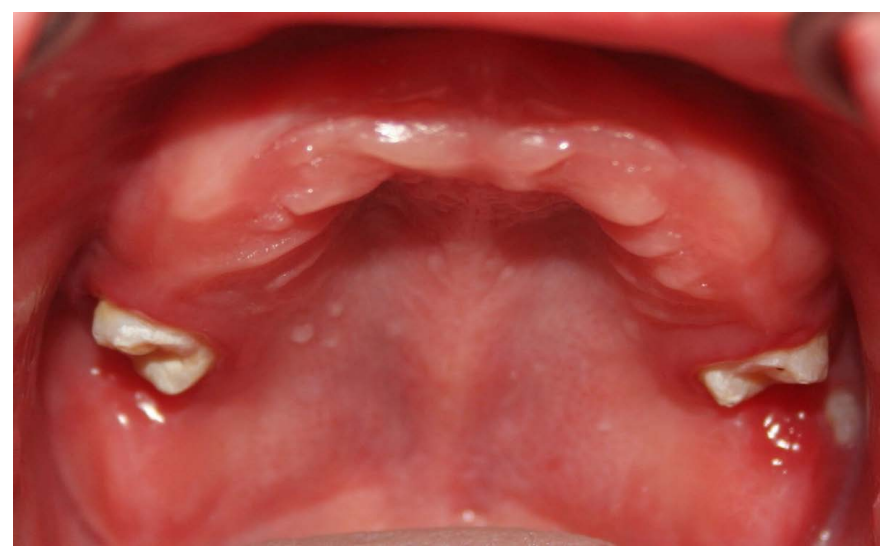

Figure 5. Maxillary occlusal view.

At the time of referring to the hospital, patient's remaining teeth included mandibular left first and second premolars and first premolar both at maxilla side (Figure 5 and Figure 6).

In clinical history, growth of the primary teeth was normal but at age of 3 , signs of dental clearance were observed and at age 4 , all primary teeth were removed from her mouth. Patient referred to pediatrician department of Tehran 


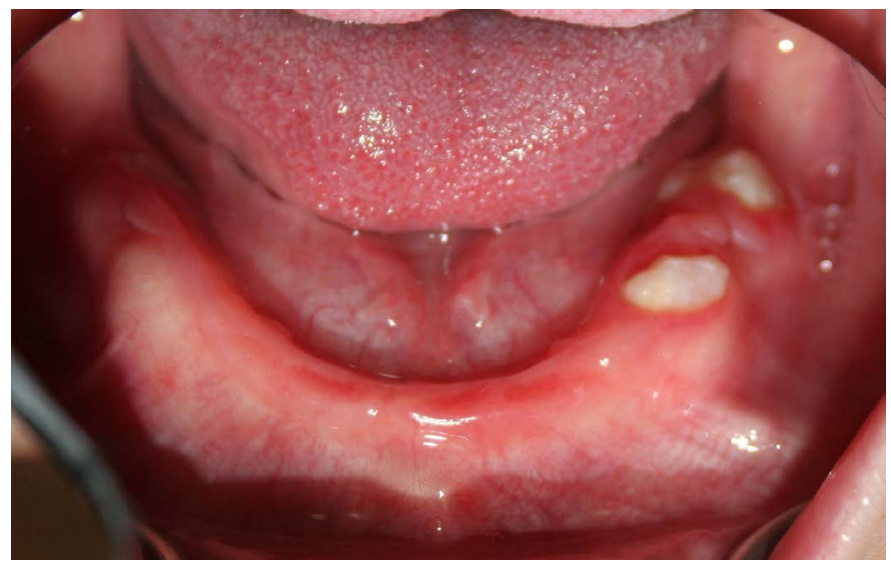

Figure 6. Mandibular occlusal view.

dentistry hospital with complaints about her early permanent teeth growth and problems about looseness and bleeding during brushing and eating. All her teeth were removed at age 7. Internal oral examination showed loss of the remaining ridge and imbalance of maxilla and mandible ridges that this loss was clear even for unerupted teeth in alveolar generalized loss radiography inspections. In order to determine the maintainable teeth, a pre-epical radiography was performed on this patient. In medical inspections, there was found no sign of systemic problem. Parents of the patient didn't have any clear historical problem but they had a familial marriage. Mother was physically and psychologically, normal only had problems of gum destruction at mandibular anterior region with calculus signs in the region. There were no sign of skin infection, ear infection, liver or pneumonia in the history of the family. Laboratory tests including complete blood count, alkaline phosphatase, and abnormal liver enzymes in which no abnormal sign was observed. In external oral inspections, there were evidences of hyperkeratosis of palms and soles clearly (Figure 7 and Figure 8).

\section{Method}

Mandibular and maxilla over denture were performed because of lack of teeth eruption. A complete process of prosthesis was done with the exception that this patient had a small jaw and there wasn't available space for initial formation, we used compact Silicone putty and light body (Figure 9 and Figure 10).

After preparation of the cast and inspection of dental undercut in semierupted teeth, a special tray was made on which border molding process was performed by green compound and the template (form) was built by forming material of compact silicone. After making the final cast, base record plus occlusion rim were built and jaw links were adjusted with lip support and oral, and external measurements were recorded in CR. According to the young age of the patient, and the limited space in the arc, we used primary teeth mould. Teeth were arranged with spaces available in order to reach a normal appearance of the teeth (Figure 11). Teeth were evaluated after being set in the mouth and denture curing process was completed and installed to the patient (Figure 12). Regarding the growing age of the patient, follow-up process was done every three 


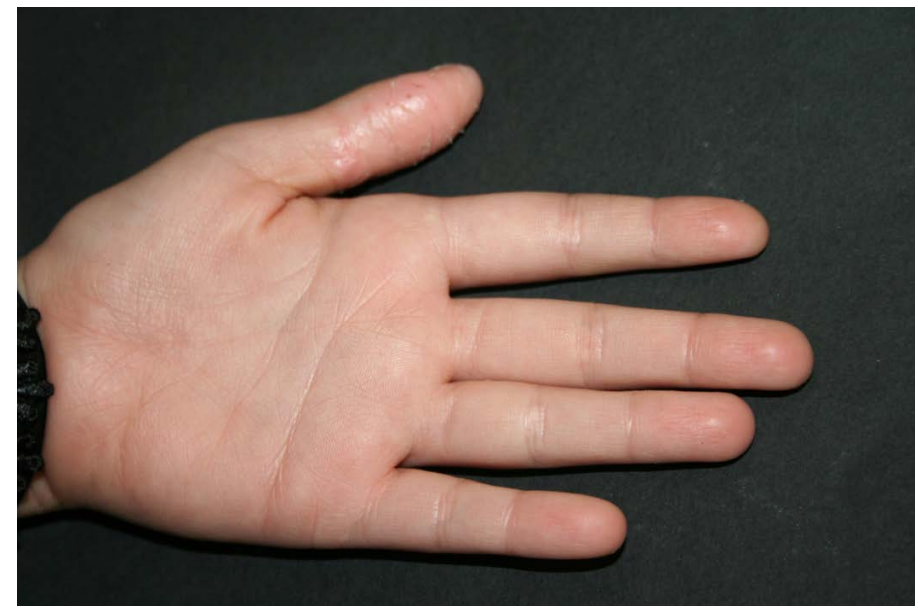

Figure 7. Palm hyperkeratosis.

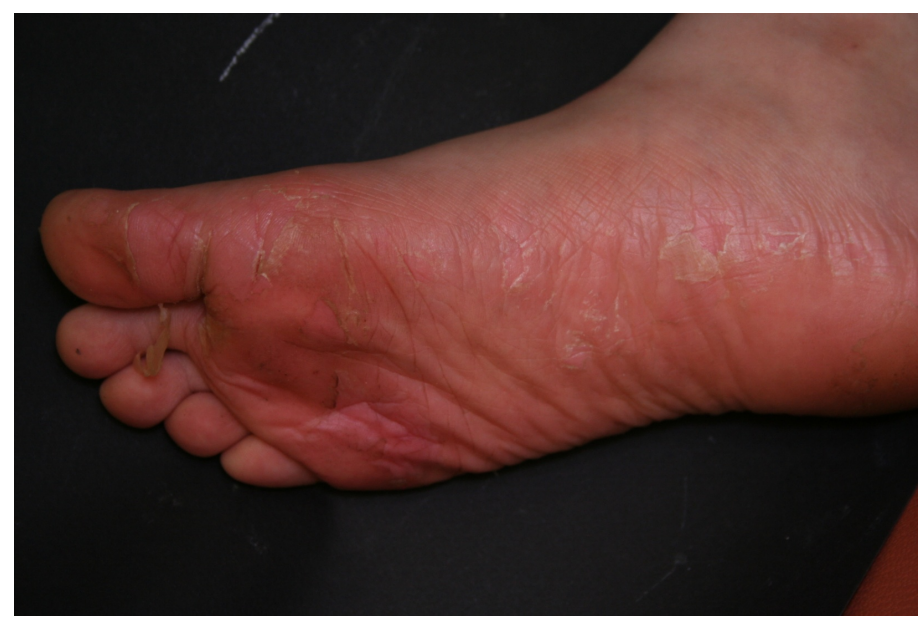

Figure 8. Hyperkeratosis of soles.

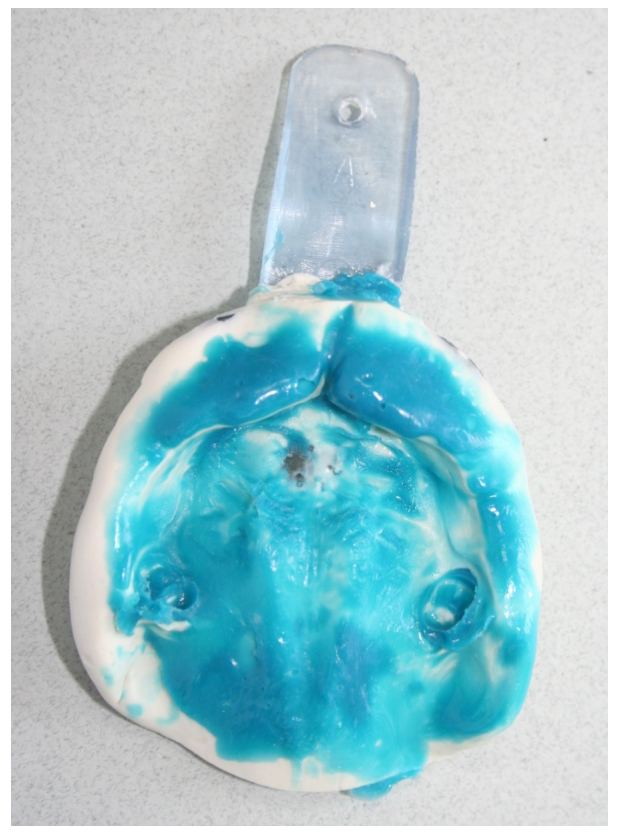

Figure 9. Primary maxilla template. 


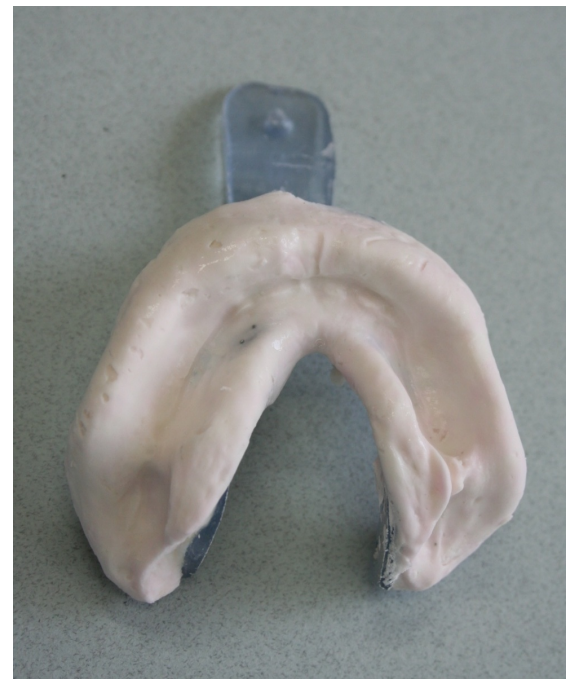

Figure 10. Primary mandibular template.

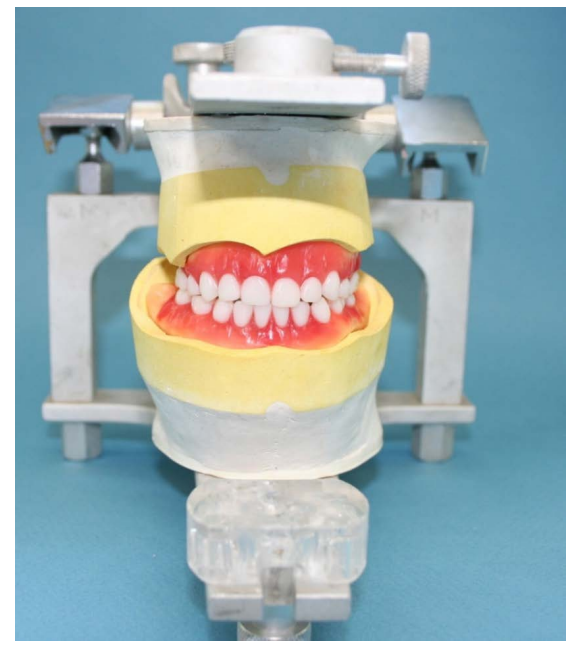

Figure 11. Arranged teeth.

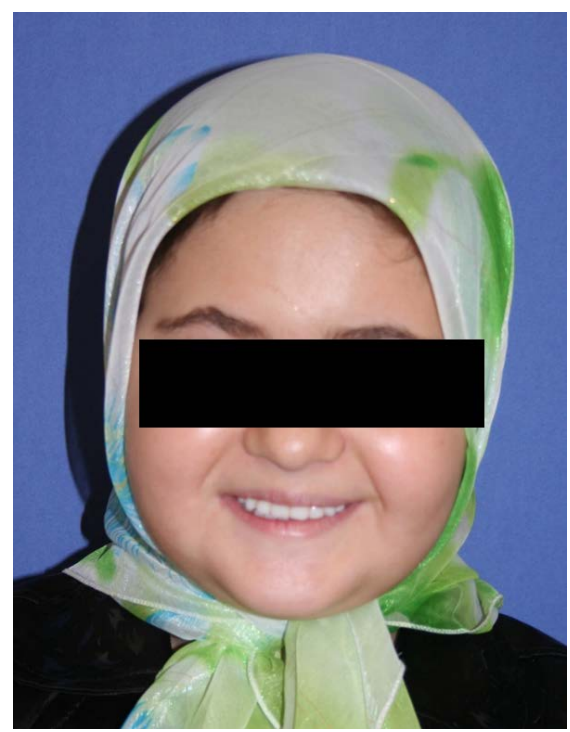

Figure 12. Installation of the teeth. 
months with the recommendation of changing the denture every two or three years, in order to prevent loss of jaw growth because of the denture.

\section{Discussion}

Papillon-Lefevre syndrome is a rare recessive autosomal syndrome determined by soles and palms hyperkeratosis and periodontal disease. Its etiological role hasn't been yet clearly defined and we don't know exactly which immunological, genetic or microbiological factors are effective in this disease [4] [5] [6].

Usually, dentists are among the first groups that determine Papillon-Lefevre syndrome at early ages and help dermatologists in this case.

In this disease, gum is inflamed after primary teeth growth which is followed by a Rapid destruction of periodontal. Diagnosis and treatment of periodontal part are very difficult. Hiam-Munk syndrome and hypophosphatemia are used for differential diagnosis [7] [8].

Psychological and social situation of the patients with Pappillon Lefevre-syndrome can be affected by losing teeth in childhood. As a result, dental inspections are essential at this age. In this disease, taking care of primary teeth include early treatments of acute periodontitis, otherwise, it is likely to have problems of alveolar loss or periodontal complaints [9] [10].

Also, prosthesis treatment is harder in patients with bone loss. Early removing of teeth instead of long-term treatment of periodontal can keep more alveolar bone and facilitate the restoration.

Over dentures are denture treatments made on the teeth or dental structures in the mouth. Using Over denture is not a new theory in dentistry and is becoming more common nowadays. The purpose of over denture treatment include: 1) The remaining teeth are as part of the residual ridge; 2) Reduce the loss of alveolar ridge; 3 ) Increase the proprioceptive sense.

Lefever syndrome is a hereditary disease that results in the loss of alveolar bone supporting the teeth and can be treated easily by over denture. Supporting prosthesis or implant is another more expensive method that was not accessible in this case because she was too young for this treatment for she has lost her vertical support of her teeth too.

\section{References}

[1] Neville Brad, W., Damm, D., Allen, C. and Boquot, J. (2002) Oral \& Maxillofacial Pathology. 2nd Edition, WB Sanndeders, Philadelphia.

[2] Hart, T.C., Suzanne Hart, P., Bowden, D.W., Michalec, M.D., Callison, S.A., Walker, S.J., et al. (1999) Mutations of the Cathepsin C Gen Are Responsible for Popillon-Lefevre Syndrome. Journal of Medical Genetics, 36, 881-887.

[3] Van Dyke, T.E., Taubman, M.A., Ebersole, J.L., Haffajee, A.D., Socransky, S.S., Smith, D.J., et al. (1984) The Papillon-Lefevre Syndrome: Neutrophil Dysfunction With Serve Periodontal Disease. Clinical Immunology and Immunopathology, 31, 419-429. https://doi.org/10.1016/0090-1229(84)90094-1

[4] Single, A., Sheikh, S., Kumar Jindal, S. and Brar, R. (2010) Papillon Lefevre Syndrome: Bridge between Dermatologist and Dentst. Journal of Clinical and Experi- 
mental Dentistry, 2, 43-46. https://doi.org/10.4317/jced.2.e43

[5] Nath, D.K., Bagchi, G. and Nath, M. (2012) Management of a Young Edentulous Patient Having Papilon Lefevre Syndrome-A case Report. Journal of Recent Advances in Applied Seiences, 27, 19-23.

[6] Senel, F.C., Altintas, N.Y., Bagis, B., Cankaya, M., Pampu, A.A., Satiroglu, I., et al. (2012) A 3 Years Follow-Up of the Rehabilitation of Papillon-Lefevre Syndrome by Dental Implants. Journal of Oral and Maxillofacial Surgery, 70, 163-167. https://doi.org/10.1016/j.joms.2011.03.058

[7] Jain, V., Gupta, R. and Parkash, H. (2005) Prosthodontic Rehabilitation in Papillon-Lefevre Syndrome: A Case Report. Journal of Indian Society of Pedodontics and Preventive Dentistry, 23, 95-98. https://doi.org/10.4103/0970-4388.16451

[8] Kressin Herforth, A., Preis, S.W.hn and Lenard, H.G. (1995) Pappilon Lefevre Syndrome-Successful Treatment with a Combination of Retinold and Concurrent Systematic Periodontal Therapy: Case Reports. Quintessence International, 26, 795803.

[9] Rateischak-Pluss, E.M. and Schroeder, H.E. (1984) History of Periodontitis in a Child. With Papillon-Lefevre Syndrome. A Case Report. Journal of Periodontal Research, 55, 35-46. https://doi.org/10.1902/jop.1984.55.1.35

[10] Brewer, A.A. (1981) Overdentures. 2nd Edition, The CV Mosby Co., St Louis, 1214.

Submit or recommend next manuscript to SCIRP and we will provide best service for you:

Accepting pre-submission inquiries through Email, Facebook, LinkedIn, Twitter, etc. A wide selection of journals (inclusive of 9 subjects, more than 200 journals) Providing 24-hour high-quality service

User-friendly online submission system

Fair and swift peer-review system

Efficient typesetting and proofreading procedure

Display of the result of downloads and visits, as well as the number of cited articles Maximum dissemination of your research work

Submit your manuscript at: http://papersubmission.scirp.org/

Or contactijcm@scirp.org 